http://jmscr.igmpublication.org/home/ ISSN (e)-2347-176x ISSN (p) 2455-0450

crossref DOI: https://dx.doi.org/10.18535/jmscr/v7i10.11

\title{
Comparison of Surgical and Conservative Treatment for Spinal Tuberculosis
}

\author{
Authors \\ Dr Richa Sharma ${ }^{*}$, Dr M.A Basit ${ }^{2}$ \\ ${ }^{1}$ Asst Prof Pediatrics, Deptt of paediatrics SLBS GMC Nerchowk Mandi \\ ${ }^{2}$ Consultant, Mannat Hospital \\ *Corresponding Author \\ Dr Richa Sharma
}

\begin{abstract}
Treatment of spine has evolved much since Percivall Pott's first description of vertebral tuberculosis. However, there are still a lot of controversies regarding the best approache for prevention of deformities. The objective of this study was to evaluate the clinical and X-ray characteristics of patients with vertebral tuberculosis and to compare the conservative treatment alone to the surgical one associated with antitubercular therapy, particularly regarding residual deformity and neurological deficit. .152 patients were evaluated: 52 were surgically treated. Among 152 patients, 100 (65\%) cases were treat conservatively with antitubercular therapy only. Remaining $52(35 \%)$ cases were treated by surgical intervention in combination with chemotherapy. In this study among 100 patients treated conservatively, $80(80 \%)$ showed significant improvement of neurological status and constitutional symptoms. Other 20 (20\%) showed no improvement or deterioration of neurological status. In this series among 52 patients treated by surgical intervention, 50 (96\%) showed significant improvement of neurological symptoms, But $2(4 \%)$ patient failed to improve neurological status even after surgical treatment.

Keywords: Tuberculosis; Spine; Kyphosis.
\end{abstract}

\section{Introduction}

The first documented case of spinal tuberculosis (TB) dates back to 5,000-year-old Egyptian mummies However first modern case of spinal TB was described in 1779 by Percival Pott ${ }^{[1]}$. Spinal involvement occurs in less than $1 \%$ of patients ${ }^{[2,3]}$ .The increasing frequency of TB has made spinal TB a major health problem ${ }^{[2,4]}$. Spinal TB (Pott's disease) is the commonest as well and most lethal forms of skeletal TB and accounts for 50\% of all the cases Although the thoracolumbar junction is the most common site but, any part of the spine can be involved ${ }^{[5]}$.The incidence of neurologic complications in spinal TB varies from $10 \%$ to $43 \%$. If left undiagnosed and not treated early may lead to major sequels such as paraplegia and deformities. The incidence of neurological involvement in patients with spinal tuberculosis is $46 \%^{(3,10)}$. There are 2 kinds of neurological deficits: early and late. The early deficit occurs during the active phase of the disease; the late deficit, as sequel. The previous occurs by direct mechanical pressure (abscess, granulation tissue, debris and caseous tissue), instability, infectious thrombosis and spinal vessels arteritis. The latter, due to spinal kyphosing, where an anterior 
transverse bone bridge compresses spinal cord ${ }^{(11)}$. Surgery for those patients with neurological deficit at the acute phase of the disease is limited to cases of conservative treatment failure, fast onset, recurrent paraplegia, uncontrolled spasticity, painful paraplegia, and instability confirmed by image. In the late phase, surgery is recommended in cases of severe kyphosis on thoracolumbar spine. Tuberculosis of the spine can be treated by both conservative and surgical approach1. It is apparent that every patient with neural complications will not be cured by antitubercular drugs and rest alone, however, all patients do not need surgical decompression as well. An absolutely conservative approach to Pott's paraplegia is considered unjustifiable as one might be losing very valuable time ${ }^{(2)}$. Irreparable damage of the cord may take place if the deterioration progresses to complete loss of motor and sensory functions. Opinion also varies regarding the role of surgery in tuberculous paraplegia $^{(3)}$. A large group of surgeons performed debridement and decompression in all cases of tuberculosis of the spine irrespective of the status of neurological involvement ${ }^{(4)}$. Others perform operative decompression only in those cases who did not respond to antiubercular drugs and rest ${ }^{(5)}$. It is difficult to strictly compare the results of various series treated by conservative and operative treatment as the clinical material varies .Routine employment of newer and more effective anti-tubercular drugs has also improved the outcome of non-operative and operative treatment ${ }^{(6)}$. Therefore this present study was undertaken to compare Surgical and Conservative Treatment for Spinal Tuberculosis.

\section{Material and Methods}

This study was designed as pragmatic randomized control trial which was carried out in the Department of Orthopedics at Mannat Hospital during the period of January 2016 to January 2019 for a period of three (03) years. All patients who were admitted with the diagnosis of spinal tuberculosis were included in the study. Clinically suspected patients of TB spine and supported by investigation findings were selected as study population. Patients were selected randomly for conservative and surgical treatment. Patients with history of spinal injury were excluded .Among 152 patients, $100(65 \%)$ cases were treat conservatively with antitubercular therapy only. Remaining $52(35 \%)$ cases were treated by surgical intervention in combination with chemotherapy. In this study among 100 patients treated conservatively, $80(80 \%)$ showed significant improvement of neurological status and constitutional symptoms. Other 20 (20\%) showed no improvement or deterioration of neurological status. In this series among 52 patients treated by surgical intervention, 50 (96\%) showed significant improvement of neurological symptoms, But 2 (4\%) patient failed to improve neurological status even after surgical treatment. The data was collected by the researcher himself. The aims and objectives of the study along with its procedure, alternative diagnostic methods, risks and benefits of this study were explained to the patients in easily understandable language and then informed consent was taken from each patient. It was assured that all information and records would be kept confidential and the procedure would be helpful for both attending surgeon and patient in making decision for management. Statistical analysis was done by one tailed $\mathrm{x} 2$ test (Fisher's exact test) using SPSS 16.0 to see the outcome of surgical and conservative treatment of the tuberculosis of the spine. The $\mathrm{p}$ value was 0.031 which was less than 0.05 at $5 \%$ level of significance.

\section{Results}

Table:-1 Distribution of Patients by age

\begin{tabular}{|l|c|c|}
\hline Age group(years) & Frequency & Percentage \\
\hline $0-10$ & 2 & $1.3 \%$ \\
\hline $11-20$ & 14 & $9 \%$ \\
\hline $21-30$ & 62 & $40.7 \%$ \\
\hline $31-40$ & 22 & $14.47 \%$ \\
\hline $41-50$ & 30 & $19.7 \%$ \\
\hline $51-60$ & 20 & $13 \%$ \\
\hline $61-70$ & 2 & $1.33 \%$ \\
\hline TOTAL & 152 & $100 \%$ \\
\hline
\end{tabular}


Table:-2 Comparision of conservative \& surgical treatment

\begin{tabular}{|l|c|c|c|c|}
\hline Treatment & Improved & $\begin{array}{c}\text { Not } \\
\text { Improved }\end{array}$ & Total & $\begin{array}{c}\mathrm{P} \\
\text { value }\end{array}$ \\
\hline Conservative & $80(80 \%)$ & $20(20 \%)$ & 100 & 0.031 \\
\hline Surgical & $50(96 \%)$ & $2(4 \%)$ & 52 & \\
\hline Total & $130(85 \%)$ & $22(15 \%)$ & $152(100 \%)$ & \\
\hline
\end{tabular}

\section{Results}

In this study 152 cases of tuberculosis of the spine show the age range from 6 years to 67 years. With the highest incidence in the second to third decade of life $(55.7 \%)$. The peak incidence was in the second decade $(40.7 \%)$. The mean age was 26.4 years with $\mathrm{SD} \pm 18.65$ years. (Table 1 )

Among 152 patients, 100 (65\%) of cases were treated conservatively with antitubercular chemotherapy. Remaining 52 (35\%) cases were treated by surgical intervention in along with chemotherapy. In this study among 100 patients treated conservatively, $80(80 \%)$ showed significant improvement of neurological status and constitutional symptoms. Other 20 (20\%) showed no improvement or deterioration of neurological status.

In this series 52 patients were treated with surgical intervention, 50 (96\%) showed significant improvement of neurological symptoms, But 2 (4\%) patient failed to improve neurological status even after the surgical intervention also (Table 2)

\section{Discussion}

The world has a population of about 7.7 billion. Of which One fourth is suffering from tuberculosis. With about 2.79 million cases of tuberculosis alone in India $^{(3)}$. Of all the total patients with tuberculosis 1 to $3.0 \%$ have involvement of the skeletal system .Spinal tuberculosis being the commonest form of skeletal tuberculosis. Spinal tuberculosis can occur at any age but it is most common during first three decades of life. In this study mean age was 26.4 years and ranged from 6 years to 67 years. The highest incidence was in first three decades $(55 \%)$ of life. ${ }^{(8)}$ series also shows highest incidence in first three decades of life and it is $73 \%$.Currently there is a tendency of involvement of adult age group particularly in the developed countries due to high incidence of AIDS, intravenous drug abuse and other causes of immune suppression ${ }^{(9)}$. Patients were selected on the basis of indication and clinical features for conservative and surgical treatment. Conservative treatment includes complete rest in bed, improvement of general heath and antitubercular chemotherapy by 4 drugs. The patients were periodically assessed clinically, radiologically and haematologically. The antitubercular drugs were continued for a period of18 months. Most of the patient improved; however, for 52cases surgical intervention was required later. The basic principle of surgical intervention was decompression by draining of pus or radical debridement. The results ofsurgical treatment were satisfactory with neurological recovery $(96 \%)$. The neurological recovery from spinal tuberculosis was $80 \%$ after conservative treatment. Those cases which failed to improve neurologically after conservative treatment within 3 months required surgical intervention. The higher incidence of neurological recovery from surgical intervention was due to careful selection of the cases, appropriate timing of surgery. Similar to the present study ${ }^{(10)}$ has performed a study on spinal tuberculosis with antitubercular drugs with surgery only for failure of paralpiegia and has shown $89 \%$ neurological recovery. In another study ${ }^{(11)}$ has performed a radical surgery with antitubercular drugs among the spinal tuberculosis patients and has found $84.4 \%$ cases of neurological improvement which is consistent with the present study result .There were certain limitation observed in the study. All cases would not be uniformly investigated for cord changes because of constraint of availability and affordability. All samples were not available for routine follow up because of various reasons like lack of awareness and socio-economic problems. Long term outcome could not be assessed.

\section{Conclusion}

This study showed that patients presenting with spinal tuberculosis improved by operative 
procedure better than compared to antitubercular chemotherapy alone. Therefore, it can be concluded that surgical treatment is significantly more effective than conservative treatment for tuberculosis of the spine.

\section{References}

1. Nussbaum ES, Rockswold GL, Bergman TA, Erickron DL, Seljeckong El. Spinal tuberculosis: a diagnosis and management challenge. J Neurosurg 1995;83:243-7.

2. Rajasekaran S, Shanmugasundaram TK, Prabhakar R, Dheenadhayalan J, Shetty AP, Shetty Dk., Tuberculosis Lesions of the Lumbosacral region. A 15 year follows up of patients treated with ambulant chemotherapy. Spine 1998;23:1163-7

3. Ousehal A, Gharbi A, Zamiati W, Saidi A, Kadiri R. Imaging findings in 122 cases of pott's disease. Neurochirurgic 2002;48(5):409-18

4. Parthasarathy R, Sriram K, Santha T, Prabhakar R, Somasundaram PR, Sivasubramanian S. Short course Chemotherapy for tuberculosis of the spine. A compamson between ambulant treatment and radical surgery -ten years report. J Bone Joint Surg $\mathrm{Br}$ 1999;81(3):464 -71

5. Mukhtar AM, Farghaly MM, Ahmed SH. Surgical treatment of thoracic and tuberculosis by anterior inter body fusion and posterior instrumentation. Med Princ Pract 2003;12(2):92-6

6. Lolge S, Maheshwari M, Shah J, Patkar D, Chawla A. Isolated solitary vertebral body tuberculosis- study of seven cases. Clin Radio 2003;58(7):545-50

7. Ramarnurthi B, Tandon PN. Texibook of Neurosurgary. (2' Edition) B.I. Delhi Churchill hivingstore Pvt. Ltd. Delhi, 2001;1:497-509

8. Tuli SM., Treatment of neurological complications in tuberculosis of the spine.

J. Bone Joint Surg. 1969;51A:680-92
9. Alici, E., Akcali, 0., Tatari, H., Gunal, I., Effect of pre- operative chemotherapy on the outcome of surgical treatment of vertebral tuberculosis : retrospective analysis of 434 cases, Arch Orthop Trauma Surg 2001;121(12): 65-6

10. Konstam PG. Spinal tuberculosis in Nigeria. Ann R Coil SurgEngl 196;32:99114

11. Kohli SB. Radical surgical approach to spinal tuberculosis. J Bone Joint Surg 1967;49B 668-73

12. Arct MW. Operative treatment of T.B. of the spine in old. 